\title{
A VISIT TO THE TROPICAL SCHOOL AT HAMBURG.
}

\author{
BY F. M. SANDWITH, M.D., F.R.C.P., \\ Gresham Professor of Medicine, Physician to Out-patients in the Seamen's \\ Hospital Society, Lecturer at the London School of Tropicul \\ Medicine and at St. Thomas's Hospital.
}

(Friday, November 15th, 1907.)

AT the end of the Fourteenth International Congress for Hygiene and Demography, held in Berlin last September, some five hundred of us were invited to visit Hamburg, where all the various institutions were thrown open for our inspection. We visited them in five groups, and I took the long-desired opportunity of spending two days at the Hamburg Tropical School. This school, which is officially called the Institute for Diseases peculiar to Ships and to the Tropics, was created in consequence of the need which the State of Hamburg felt for practical and scientific research into marine and tropical diseases. The site was well chosen, because the sanitary service of the port furnishes excellent material for the work. The Institute was also founded to give special instruction to medical officers of the mercantile marine service.

In the year 1900, following close upon the creation of the London and Liverpool Schools of Tropical Medicine, the old Seamen's Hospital at Hamburg was converted into the Institute, and a new two-storied hospital of fifty-six beds was built in the same compound for the reception of tropical patients, especially seamen.

The Imperial Government of Germany determined about the same time to establish a training school for officers of 
the Colonial Medical Service, and instead of opening this in Berlin they formed a coalition with the State of Hamburg, by which they, while retaining certain rights and granting money in aid, ensured for their naval officers tuition in the Institute and adjoining hospital. The Institute at Hamburg, therefore, has the advantage of officially belonging both to the Imperial Government and to the State of Hamburg, and when money cannot be obtained from one of these sources it is often easy to procure it froin the other. This doubtless accounts for the fact that the financial position is never strained, and though $I$ have made many inquiries $I$ have not yet succeeded in finding anyone who could tell me what the annual budget amounts to. The whole establishment is under Government and Municipal control, and is not dependent, as our English Tropical Schools are, on the benefactions of the public. I should also mention that grants in aid seem to be obtained from the War and Marine Ministries.

Another advantage which the Hamburg Institute has is that it was considered important from the very beginning that it should be in close touch with the sanitary service of the port, and therefore Dr. Nocht, the port medical officer of the city, was appointed Director of the Institute, and has his chief office in that building.

In 1906 the Institute was found to be too small, and was therefore enlarged; zoological laboratories were added, under the care of the late Professor Schaudinn, who has now been succeeded by Dr. von Prowazek.

\section{Description.}

The Institute stands on a hill in the centre of the docks, about half an hour by tramway from the heart of the town. On the ground floor are the Director's room, other offices, and a research laboratory for four workers. On the first floor is the library and reading-room. Two lady librarians 
are in charge, the books are catalogued by the card system, and recent additions have been made to it by buying Professor Schaudinn's books. The library subscribes to seventy-seven periodicals, and exchanges Transactions with many institutions; the library expenses amount to about $£ 250$ a year. The laboratory, built in 1906 , is $58 \mathrm{ft}$. long by $19 \mathrm{ft}$. wide, with six large windows, and is fitted with gas, water, and electric light for twenty-four students.

The museum is arranged round the sides of the laboratory, and a good epidiascope exists. On the same floor there is a chemical laboratory of two rooms, another room for experimental operations on animals, without legal restrictions, and some smaller laboratories. On the second floor is the protozoology laboratory consisting of three rooms for five workers, a tropical room kept at a temperature varying between $77 \mathrm{deg}$. and $86 \mathrm{deg}$. Fahr., and a relative humidity from 60 to 70 per cent. This serves for the breeding and development of mosquitoes, flies, ticks, snakes, etc. The ticks I saw were kept between two layers of tripod tables, enclosed in glass jars, with lids of wire gauze weighted with lead, and enclosed in tins of double saucers, containing petroleum or vaseline.

A museum of tropical hygiene is in course of arrangement, but all that was shown to us was a model of a mosquito-protected bed. There is a club-room for students, but there are no residential chambers for them in the building.

In the basement there is a room for micro-photography and a dark room with red walls, an automatic washingtray, and an electric ventilator for drying plates.

On the ground floor of the hospital there are two wards, each of fourteen beds, one of which is supposed to be reserved for coloured patients, but at the time of my visit there were several Europeans suffering from typhoid fever in the native ward, Each typhoid patient was surrounded 
by a large mosquito net to minimise infection. A small operating-room was on this floor also.

On the first floor there was another ward of fourteen beds, a smaller ward and several rooms for one or two patients, with large terraces overlooking the harbour and garden. The second floor is devoted to the sisters' quarters.

The kitchen of the hospital is in the large seamen's house in the same compound, which is a sort cf club for sailors. The patients' fees are as follows: those in the first class pay $7 s$. a day if they come from Hamburg, or are employés of the Colonial Office, while ordinary patients pay 10s. In the second class they pay respectively $4 s$. or $6 s$. and in the third class $2 s .6 d$. or $3 s .6 d$. per day.

The total number of patients admitted to this hospital from 1901 to July, 1907, is 3820 , which gives an average of about 588 per annum. The stables consist of two wings, somewhat small and ill-ventilated. The dogs had had their inferior laryngea! nerves cut to prevent their barking. Near the stables is a mosquito house, with a cemented tank, for breeding different kinds of mosquitoes.

\section{Course for Studen'rs.}

This is both practical and theoretical; there is a short course held twice a year, lasting only three weeks, for the medical officers of ships. During this time they are taught the hygiene of vessels, including food and water examination, care of the sick on board, the duties of a ship doctor, such as the prevention and stamping out of infectious diseases, quarantine and disinfection, and practical information about malaria, sleeping sickness, kala-azar, yellow fever, scurvy, beri-beri, Malta fever, plague, cholera, typhoid, dysentery, and helminthology.

The tropical course lasts ten weeks, and is also held 
twice in the year, special attention being paid to protozoology. The syllabus comprises the histology and pathology of blood, mosquitoes, malaria, blackwater fever, trypanosomes of men and animals and their carriers, piroplasmosis, kala-azar and Delhi boils, tick fever and relapsing fever, syphilis, yaws, verruga Peruana, spirillar diseases of domestic animals, yellow fever, dengue, filariasis, ankylostomiasis, bilharziasis, paragonimiasis, parasitic flies, poisonous animals, dysentery, liver abscess, sprue, Madura foot, beri-beri, scurvy, leprosy, plague, Malta fever, cholera, typhoid fever, hygiene of ships, tropical hygiene, care of vaccine lymph in the tropics, cattle plague, bovine tuberculosis and horse sickness. Veterinary surgeons are sometimes sent to attend part of the course by the Colonial Office, and others join privately.

Since the beginning, 349 graduates have passed through the Institute, 115 of these being colonial officers, including seventeen veterinary surgeons: thirty-one have been naval doctors, seventy-nine doctors of the merchant service, eighty-three private practitioners, and the remaining fortyone were foreign students. Among the latter class many nationalities have been represented: Hungarians nine, Dutch nine, Swedes, Swiss, Russians, Japanese, Brazilians, Bulgarians, and one each from Belgium, England, and Australia.

Fres.

Three guineas are paid for the short course, and double that sum for the tropical course, while the Hamburg doctors pay no fees.

The clinical material in the hospital during the last six years has comprised 1578 cases of malaria, eighty-three cases of dysentery, mostly amcbic, seventy-one of blackwater fever, 145 of beri-beri, two cases of trypanosomiasis, besides patients suffering from various worm infections, yaws, liver abscess, sprue, and leprosy. 
The students in the laboratory are given opportunities of making for themselves a collection of microscopical specimens of most of the cornmon tropical diseases. They are instructed in the examination of meat at the Hamburg slaughter-house. Advanced students are welcomed for research work in the Institute. Special lectures are given to nurses and missionaries who are proceeding to the tropics, and some lectures have been given to lay audiences. Illustrated postcards are published to instruct lay residents in the tropics.

The Institute has so far not been able to send any scientific expeditions to the tropics, but hopes are entertained that this will be possible in the near future. I may, however, mention that in 1904 Drs. Otto and Neumann proceeded to Brazil in order to study yellow fever, and in the following year Dr. Otto went to Togo, West Africa, for the same purpose. In 1906 Drs. Fülleborn and Mayer travelled in Egypt, Ceylon, India, and East Africa, to study tropical diseases, and all these journeys have been amply utilised to enrich the pathological museum.

For teaching purposes lantern slides are largely employed, and there are some excellent coloured diagrams, which are shortly to be reprinted for sale.

In order to give every facility to students to study helminthology, sections of worms are placed vertically in stands with electric light behind them; the student examines these at leisure with a magnifying glass. There is a splendid collection of microscope slides for demonstration purposes, and a good supply of photographs. Tsetse flies are sent to Hamburg from the tropics in the pupa stage, so that they develop into mature insects either on bourd the ship or after arrival at the Institute.

I had the advantage of attending an epidiascope demonstration given by Professor Fülleborn, when due honour was paid to the various workers of this country who have 
made discoveries in tropical medicine. Dr. von Prowazek showed us newly-discovered protozoa in trachoma from Sumatra, and Herr Giemsa, the chemist, explained to us by diagrams, the Nocht-Giemsa apparatus for killing rats on ships. The gas derived from combustion of coke requires twelve hours to disinfect a large passenger steamer. We saw some rats killed with this gas in half a minute in a bell glass, and it is believed that all rats are destroyed on a steamer in about ten minutes after exposure to the gas. The gas consists of about 8 per cent. carbon monoxide, with a little carbonic acid, and some 70 per cent. of nitrogen.

The cost of disinfecting a moderate-sized steamer is £7 108. In adilition to the compulsory destruction of rats on vessels arriving from a plague-infected port, owners often request that rats, when a nuisance on a ship, should be killed by this method. The Giemsa apparatus does no harm to any cargo, and has this great advantage over Clayton's sulphurous-acid process.

When a ship arrives from a plague-infected or suspected port the rats on board are examined, especially when it is reported or discovered that any have been found dead or dying. For this purpose sample rats are sent to the Hygiene Institute, of which Professor Dunbar is the Director. If the post-mortem examination of the rat shows plague or anything suspiciously like it, all the rats on board that steamer are destroyed beforo the cargo is landed. The crew are disembarked in a special place before fumigation begins, and are not allowed to return to the ship until the air has been tested by animals in cages to make certain that no dangerous gas-poisoning remains. The Nocht-Giemsa apparatus introduces gas into the hold and on completion of the process exhausts it again. Though the gas kills rats successfully, it does not disinfect the cargo, which must therefore be carefully removed by 
specially-protected workers into rat-protected stands. When a case of human plague has occurred on board, the clothes and bedding are sterilised and the water used during this process is boiled before it is allowed to flow into the Elbe.

On the fifteen ships first submitted to this process, 2845 rats were killed, of which 150 , or 5.2 per cent., were plague infected; in the same ships 184 mice were killed, of which only one was proved to have plague.

It would have been impossible for me to have profited so much by my two days' stay at Hamburg if it had not been for the great courtesy of Dr. Fiulleborn, who most kindly devoted some hours to explaining the methods of work to two or three of us.

I have, I hope, shown that the Hamburg Tropical School is full of vitality, and doing excellent work. Enjoying, as it does, liberal financial support from the Government, it is already in a more favourable position than the Tropical Schools of London and Liverpool, and England must look to it that she be not left behind in the friendly competition for increased knowledge in the vital subjects of tropical medicine and hygiene. 